\title{
La turista feminista y el arte Mithila en India y Nepal. Consumismo por el desarrollo de la mujer moderna
}

\author{
Andrea DE LA RuBIA GómEZ-MorÁN \\ Universidad Autónoma de Madrid \\ Departamento de Historia del Arte \\ adlrubia@hotmail.com
}

Recibido: 09-01-2014

Aceptado: 29-09-2014

\section{RESUMEN}

El arte Mithila, hecho tradicionalmente por las mujeres de India y Nepal, ha experimentado grandes cambios en los últimos años desde la aparición del turismo y las ONGs, que han convertido esta práctica milenaria en un arte comercializado con el fin de colaborar al desarrollo de la "mujer del tercer mundo" mediante la venta de su trabajo creativo.

Palabras clave: Arte Mithila, ONG, feminismo, turismo, globalización, mujer del tercer mundo.

\section{The Feminist Tourist and Mithila Art in India and Nepal. Consumerism for the Development of the Modern Woman}

\begin{abstract}
Mithila art, traditionally made by the women from India and Nepal, has experimented huge changes in the last years since the emergence of tourism and NGOs, which have transformed this ancient practice into a commercialized form of art on the aim of collaborating in the development of the "third world women" through the sale of their creative work.
\end{abstract}

Key words: Mithila art, NGO, feminism, tourism, globalization, Third World women. 
Este estudio versa sobre la situación y cambio del arte Mithila, realizado por las mujeres pertenecientes a la cultura maithili desde los tiempos antiguos hasta la situación actual, analizando esta cultura desde un punto de vista histórico y antropológico, y adoptando una postura crítica con ambos términos.

Trinh T. Minh-Ha describe la antropología como la ciencia que estudia la especie humana y que analizando ritos, tradiciones y culturas vuelve al nativo mudo e indefenso ante la "gran verdad", que es lo que esta ciencia describe. ${ }^{1}$ La antropología es por tanto algo cínico que gobierna al individuo al igual que lo gobierna el lenguaje pues, por mucho que intentemos reducir el lenguaje como puro instrumento, siempre triunfa en dar al texto un estatus de gobernabilidad sobre el otro por su definición a través de la palabra. La idea antropológica de "mujer del tercer mundo" ha tenido enormes consecuencias para el arte Mithila y es por ello que este texto trata de realizar un análisis de este arte partiendo de la antropología con el fin de desconectarla, y así llegar a su destrucción en su papel como ciencia hegemónica.

Trinh T. Minh-Ha se pregunta cuál es el método más adecuado para acercarse a otro ser humano. Cuando uno a su vez no quiere caer en la definición y el estudio como ciencia, ¿se puede formalizar un estudio sin ser antropológico? Algunos antropólogos experimentales han optado por crear sus textos etnográficos en forma de diálogo con la cultura a estudiar. Como dice Clifford en su libro Writing Culture, esta forma de estudio hace que la autoridad del discurso sea cuestionada, revelándose como una característica que representa la cultura y abriendo en el diálogo cuestiones y diferentes puntos de vista que pueden ser confrontados. ${ }^{2}$

Spivak dice que es tiempo de repensar y reconstruir el feminismo y las relaciones con estas mujeres no viéndolas ya más como unas víctimas que necesitan nuestra ayuda, sino respetando su propia visión sobre su cultura y la verdad sobre su condición. En lugar de etiquetar a estas mujeres como pobres y subdesarrolladas, Spivak propone que aprendamos de ellas, las hablemos y desarrollemos un modo distinto de leer su cultura, tratando que la división de "mujer privilegiada" y "mujer pobre" sea eliminada de nuestros pensamientos. ${ }^{3}$

Este estudio por tanto plantea la siguiente cuestión: ¿Dónde queda lo auténtico de este arte, especialmente cuando es transformado en un arte para turistas? El arte Mithila para el turista puede haber perdido en cierto modo su autenticidad como arte tradicional, pero por otro lado su apertura a nuevas ideas puede haber enriquecido sus medios y modos de creatividad. Trinh T. Minh-Ha describe la autenticidad como la necesidad de apoyarse en un origen que no puede ser negado y que a su vez provoca temor a perderlo, pues perder el origen es perder la base de la cultura. Este miedo puede ser algo que paralice la evolución pues puede provocar un freno a la entrada en el infinito proceso de la interacción, el intercambio y la apertura a nuevas ideas y fuentes diversas. (Fig.1.).

1 T. MINH-HA, Trinh: Woman, Native, Other. Writing Postcoloniality and Feminism. Indiana University Press, Bloomington and Indianapolis, 1989.

2 CLIFFORD, James y MARCUS, George: Writing Culture: The Poetic and Politics of Ethnography. School of American Research. University of California Press, 1986.

3 CHAKRAVORTY SPIVAK, Gayatri: In Other Worlds. Nueva York: Routledge, 1998. 


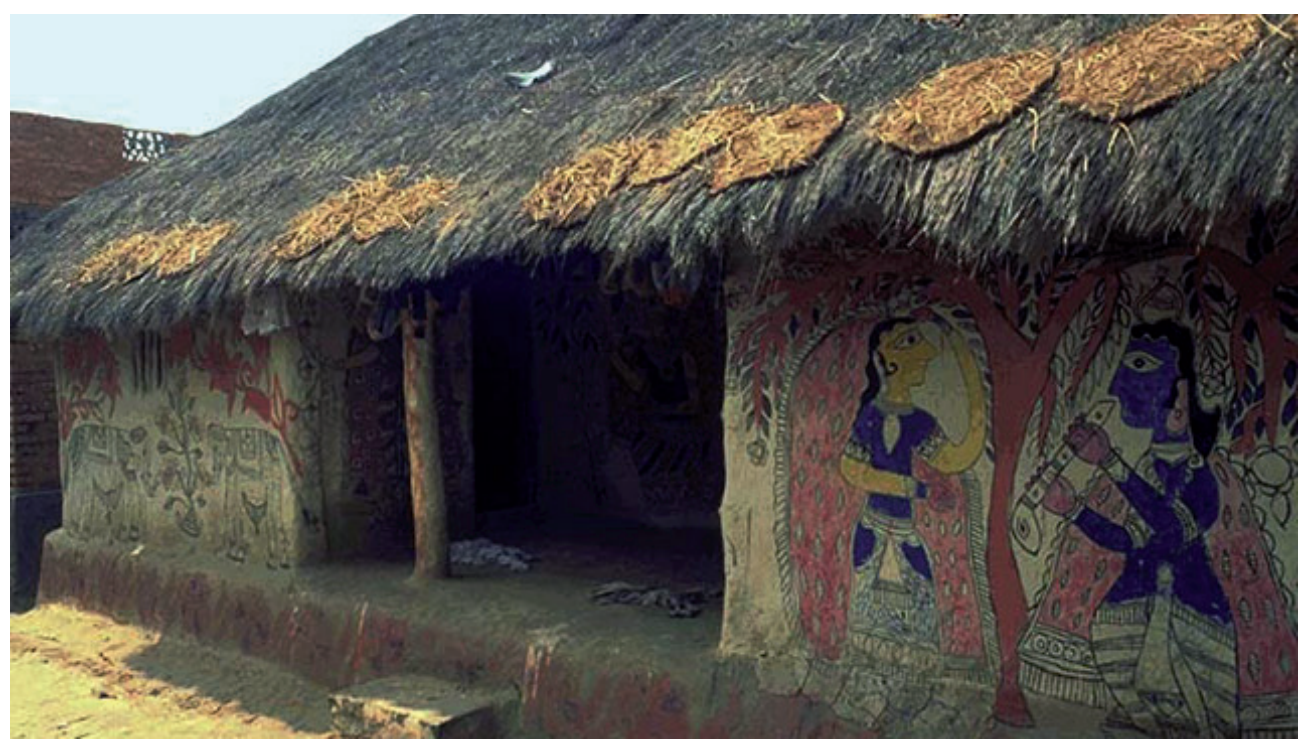

Fig. 1. Mithila, pintura de pared.

Sin embargo, hay que tener en cuenta que la transformación en este arte se ha producido por causa de la invención occidental de la necesidad de la "mujer del tercer mundo". Esta invención siempre va de la mano del impulso de ayudar a los demás como una tarea noble y gratificante, que hace sentir al que ayuda como el salvador del necesitado.

El feminismo occidental imagina a la mujer hindú y nepalí como alguien necesitado a quien debemos ayudar, y ha fomentado la transformación de su arte en un producto comercial cuyo objetivo es ser vendido para paliar estas necesidades y otorgarle así poder y libertad. Entre la cultura maithili y el turista está bien presente el concepto de la diferencia, que denuncia la opresión de las mujeres del tercer mundo mediante términos y nociones hechos para encasillarlas en un criterio definido por las mujeres europeas y americanas. Trinh T. Minh-Ha sostiene que la diferencia es lo que mina la idea de identidad, pues es la identidad la que marca la diferencia. Decir que todas las mujeres sufren la misma opresión simplemente por el hecho de ser mujeres es negar los diferentes tipos de patriarcado existentes. ¿Entonces, cuál es la realidad de la cuestión? ¿Se ha desvalorizado el arte Mithila al perder sus formas tradicionales, o se ha enriquecido al abrirse a nuevas formas de representación de su arte?

El nombre Mithila se remite a la capital del antiguo reino de Videha en Nepal, el cual abarcaba el actual estado de Bihar al norte de la India y el estado de Mithila al sur de Nepal. La cultura maithili comenzó en esta zona al menos a partir del siglo XIV, y ha continuado hasta hace muy poco tiempo, siendo un arte transmitido de madres a hijas por tradición y rito.

El reino de Videha llegó a su fin cuando la British East Indian Company y el Rey Gurka de Nepal firmaron el Tratado de Sigauli en 1816, que dividió el territorio 
nepalí en dos mitades desiguales. Los Británicos se quedaron con la mayor parte del terreno al sur, que pasó a ser parte de la India, mientras que Nepal pudo recuperar la zona norte, significando este tratado el fin de la guerra Anglo-Nepalí por la lucha de este terreno, que había sido invadido por los Británicos en la expansión colonial. ${ }^{4}$

La cultura maithili tiene su propio lenguaje y tradición, en donde la mujer juega un papel significativo en la pintura y en la artesanía sin diferencia de castas ni religión, aunque si se perciben ciertas tendencias y estilos diversos según la casta a la que pertenezca la artista en el modo de representación. Para el Dr. Kailash K. Mistra, la pintura Mithila puede ser vista como un tipo de escritura a través de la cual las mujeres comunican su expresión de forma estética. ${ }^{5}$ Así, a través de este tipo de escritura particular, las mujeres maithili comunican sus sentimientos y libertad de pensamientos. Realizaban estos dibujos utilizando el método de la aripana, que consiste en arroz molido con agua hasta conseguir una pasta llamada pithar. Con esta pasta la mujer pintaba con los dedos diseños geométricos, añadiendo mas tarde a este diseño pigmentos vegetales. (Fig.2.).

Las artistas Mithila juegan con los aspectos psicológicos que cada color les aporta. Por ejemplo, la energía y pasión puede verse representada a través del uso del rojo y el amarillo como monocromos que se utilizan sobre grandes superficies en la pintura. La concentración de la energía y la fuerza está bien representada en el rojo, mientras que el verde es usado en motivos vegetales como hojas y tallos. Las mujeres brahmanes prefieres utilizar colores muy brillantes, mientras que las kayasthas optan por colores más apagados. ${ }^{6} 6$ Esta decoración era utilizada para el culto a las deidades y consistía en representar, sobre las paredes, alfarería y patios de sus casas, a los diversos dioses, diosas hindúes, imágenes de fertilidad y seres mitológicos, con el fin de atraer la bendición sobre matrimonios y otros eventos importantes. (Fig.1.).

Las pinturas Maithili son realizadas por muchos motivos diversos, casi todos relacionados con fiesta y celebración. Por ejemplo el festival de Tusari Pooja, en el que las niñas no casadas dibujan en su aripan un templo, el cosmos y los dioses, para tener buenos maridos en el futuro. También está el Sasthi-Pooja Aripan que se realiza cuando las niñas tienen la primera menstruación. En este aripan se representa el universo y su destrucción ${ }^{7}$. En la fiesta de Deepawali, las mujeres decoran la fachada de sus casas para invitar a Laxmi, diosa de la prosperidad, a entrar en ellas mediante pinturas de elefantes embarazados, símbolo de prosperidad. También representan el Gatra-Sankrant Aripan, símbolo del nacimiento y la muerte. Un elemento en común

\footnotetext{
4 “About Mithila" [en línea] Arts of Nepal, 2011. http://www.artsofnepal.com/about/1/7/Mithila. html[Consulta: 3 de febrero 2014].

5 K.MISHRA, Kailash: "Mithila Paintings: Past, Present and Future" [en línea] India Gandhi National Centre for the Arts. http://www.ignca.nic.in/kmsh0002.htm [Consulta: 26 de enero 2014].

6 El paso de las pinturas naturales, muy costosas de hacer, a las pinturas sintéticas, ha supuesto un ahorro de tiempo para las mujeres de la cultura maithili debido a todo el esfuerzo que debían de emplear en producir los colores necesarios. Hoy en día tienen toda clase de colores en el mercado, los cuales viene en polvo y se mezclan con leche de cabra.

7 Durga junto a su tigre es otra representación muy común de este aripan. La flor de loto, la diosa de la riqueza Lakshmi, Ganesha, Krishna y Siva son los dioses más representados junto a árboles, pájaros y motivos vegetales.
} 
de las pinturas Mithila es la diosa-serpiente, una forma de serpiente que representa a la diosa Nag Panchmi durante los monzones, tiempo en que estas abundan. El arte de estas mujeres es transitorio, pues las lluvias en la época de los monzones borran las decoraciones, o se cubren de barro durante el festival Jursital en primavera. ${ }^{8}$

Sin embargo, la celebración más relacionada con el arte Mithila es la del matrimonio, en la cual se decora la habitación Kohabar. La antropóloga estadounidense Claire Burkert, que ha estudiado las diferentes manifestaciones artísticas y su significado dentro de esta comunidad rural, afirma que el Kohabar es una habitación en la casa de la novia donde la pareja pasa su primera noche de bodas. El tema central de estas pinturas es la fertilidad, y su intención la de bendecir a la pareja que se acaba de unir en matrimonio. Su objetivo principal es el de incrementar la potencia sexual y fertilidad de ambos, la esposa y el marido. ${ }^{9}$ Aparte del Kohabar, también se decoran el Gosaighar, una habitación especial para los dioses de la familia, y el KohabarGharak-Koniya o pasillo fuera del Kohabar. Durante la ceremonia del matrimonio los esposos son separados por las mujeres con el fin de realizar su propia ceremonia devota a Gauri en el Gosaighar, y en la cual los hombres están prohibidos. Gauri, es la diosa a la cual la novia ha rezado desde niña para conseguir un buen marido.

$\mathrm{El}$ arte Mithila ha sobrevivido durante generaciones, a causa de su eficaz organización social, basada en la vida de comunidad y el papel de las mujeres maithili en la tradición de la sociedad rural. (Fig.3.).

En la cultura india y nepalí se cree que, en toda creación del ser humano, está implícita la conexión con los dioses, y muchas preguntas de la vida diaria son contestadas por medio del arte a través de los mitos y la religión. Las imágenes Mithila son elaboradas con precisión, en donde tamaño, textura y forma son fáciles de recordar e imaginar; es un lenguaje poético que evoca la protección de los espíritus y una alianza con la imagen en el deseo de transformarse en el dios o la diosa que invocan. La religión es uno de los pilares fundamentales en esta cultura, y es, a través de ella, donde podemos encontrar las raíces del estatus de la mujer en la sociedad rural o urbana, hasta bien entrado el S. XX. Existen ideologías, dentro de la religión Hindú, que influyen considerablemente en el rol que desempeña la mujer en la sociedad. La capacidad reproductora es controlada, a través del matrimonio antes de la pubertad, entre otras prácticas. Una vez casados, la novia se muda junto con su dote a la casa de su marido, viéndose sometida al mismo desde muy temprana edad y en un lugar desconocido para ella.

\footnotetext{
8 GHIMIRE, Bijaya: "Mithila Arts. Nepalí Art" [en línea] http://www.weallnepali.com [Consulta: 30 de enero 2014].

9 La decoración del Kohabar se basa en diseños tántricos. En el centro se pinta una caña de bambú que simboliza al hombre y alrededor hojas de loto que simboliza a la mujer, con loros como imágenes de una unión feliz, y tortugas y pescados que representan la reencarnación del dios Visnú y la sexualidad femenina y masculina. Otro de los temas favoritos con los que se puede decorar esta habitación es la representación de Krishna tocando la flauta y observando a las Gopis o pastoras. La gente de la cultura maithili son oradores de Sakti con la influencia de rituales tártricos, por lo tanto Siva-Sakti, Kali, Durga, Ravana y Hanuman aparecen también en sus murales, rodeados por montes o simplemente por motivos florales como fondo.
} 
Su estatus va mejorando con los años, hasta que llegue una nueva esposa que la sustituya en los trabajos domésticos. ${ }^{10}$ Esta idea de la adquisición de la mujer forma parte de la ideología religiosa Hindú, que ve a la mujer como mano de obra y procreadora de niños que serán el sustento de su vejez.

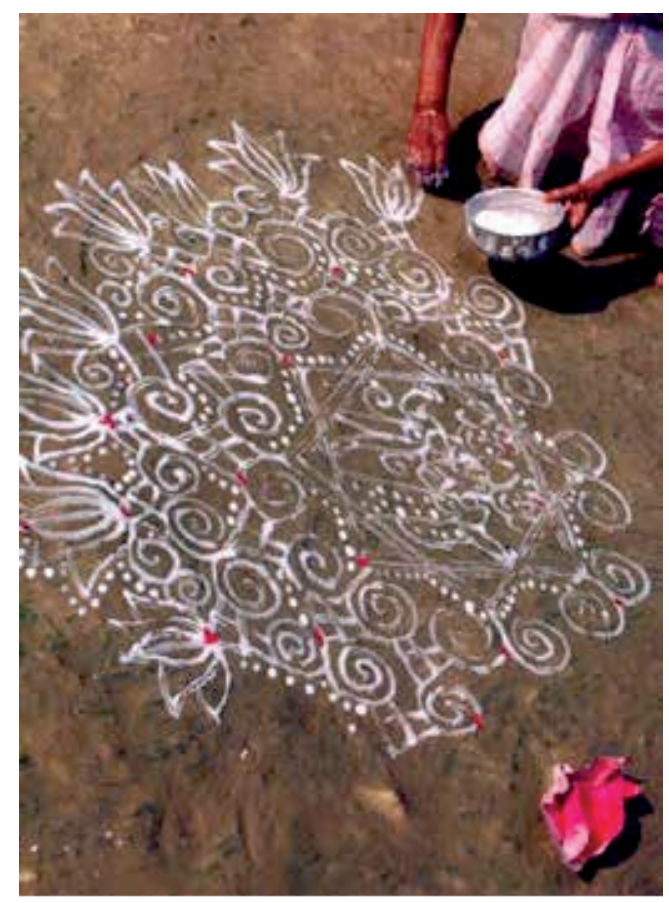

Fig. 2. Aripan, pintura de suelo ritual, Madhubani, Bihar.

La separación de sexos ha sido tema fundamental para la organización de la sociedad. La mujer cuenta con el hogar como único espacio social de reproducción y trabajo doméstico. Sin embargo, a partir de la época colonial este espacio se expandió hacia el exterior emergiendo dos nuevas instituciones sociales: el colegio y la política. Unos de los primeros defensores de los derechos de la mujer en India fue Mahatma Gandhi que vio el error que era creer en las tradiciones del pasado por considerar a la mujer negativa e impura dentro de la sociedad hinduista. Gandhi acusaba la falta de educación, la dominación cruel del hombre, la violencia doméstica y la mentalidad de esclava con la que la mujer había sido educada. El progreso de igualdad que inicio Gandhi está llevando a reconocer la contribución artística, económica, científica y política de la mujer en la India, aunque este reconocimiento no ha llegado aún a las mujeres del mundo rural.

10 COFÁN FEIJÓO, Fátima: "La producción creativa de la mujer hindú en la India y Nepal del siglo

XX" en Geografias de la mirada. Género, creación artística y representación. Marián López F. Cao editora, Madrid, 2001. 
En la India contemporánea la artista del medio urbano, normalmente educada en Europa y América, contrasta con la artista del medio rural sin oportunidad y en donde la tradición religiosa sigue prevaleciendo por encima de todo. Las artistas del medio urbano pertenecen a una clase acomodada e intelectual en donde se valoran sus conocimientos y se pasa por alto la tradición más férrea. No existe tanta discriminación en cuanto a su posición en la sociedad, y se respeta y apoya más su creación artística. Por otro lado, las mujeres rurales, ayudadas por organismos internacionales, han comenzado a comercializar sus pinturas en el mercado turístico consiguiendo a través de esto una solvencia económica que les permite un lugar en la sociedad patriarcal, como es el caso de la comunidad de Janakpur en Nepal.

Los primeros pasos hacia la comercialización del arte Mithila y su traspaso del muro de barro al papel hecho a mano, se dio en torno a los años sesenta con el objetivo de crear una oportunidad de trabajo para las mujeres de la zona rural de Janakpur, que necesitaban dinero para ayudar a la comunidad a afrontar la cruenta sequía que había desolado la zona. Fueron las mujeres brahmanes las que comenzaron a pintar el arte Mithila sobre papel. Las mujeres de altas castas no pueden cruzar el límite de sus casas según la tradición, y durante la sequía la única forma de ayudar económicamente a su familia fue la de dibujar sus pinturas en papel desde su hogar para luego venderlas. ${ }^{11}$

En un principio el paso de estos dibujos del muro al papel tuvo escaso éxito pero ciertamente representó un comienzo simbólico de apertura de este arte a un nuevo mundo. Se podría afirmar por tanto que, las mujeres maithili, pasaron de tener motivos religiosos y tradicionales a motivos económicos, quizá influenciadas también por la introducción de la sociedad consumista por la vía del turismo. Según Spivak, la oposición binaria entre economía y cultura está hoy profundamente entretejida, y su complicidad actúa en la mayoría de las decisiones que tomamos.

Hoy en día, existen una serie de organismos internacionales que por causas solidarias apoyan y refuerzan a las mujeres maithili en la práctica de su arte tradicional convertido a un arte comercial. Las ONGs comenzaron su trabajo en la Nepal a partir de los años cincuenta. En 1990 tras el Movimiento del Pueblo y la llegada de la Democracia al país, las ONGs recibieron un gran reconocimiento y el financiamiento extranjero fue incrementado. ${ }^{12}$ Claire Burkert descubrió los trabajos que realizaban las mujeres de la comunidad de Janakpur y, con ayuda del gobierno Japonés, fundó en 1989 un centro destinado exclusivamente a mujeres, conocido como Janakpur Women's Development Center (JWDC), dedicado fundamentalmente a promover el conocimiento, libertad y prosperidad de la mujer mediante su estimulación a continuar pintando y a no perder sus tradiciones ancestrales de representación de imágenes, ya sean religiosas o escenas de su propia vida.

11 Diez años después las kayasthas se les unieron con un nuevo estilo propio, y ha sido hasta hace poco que a las harijan no se les permitía experimentar con este arte y los nuevos medios.

12 Sin embargo, resulta curioso por no decir sospechoso que la transición nepalí hacia la Democracia ocurriese en un tiempo en el que la asistencia de medios y financiación extranjera estaban muy presentes en la sociedad civil. Con el inicio de la Democracia, toda esta financiación fue a parar a la fundación de nuevas ONGs extranjeras, cuyos objetivos impuestos iban por su puesto a la par que la economía mundial y la moda de la política liberal. 
Según Bukert, desde que se fundó el JWDC, las mujeres pertenecientes a esta comunidadhandesarrolladonuevashabilidadespara plasmar su pintura sobre papel, en donde las figuras de perfil y grandes ojos carecen de perspectiva. Los elementos que toman de la naturaleza, como pueden ser hojas, flores de loto, loros o peces, llenan el espacio prestando especial atención al aplicar el color. Para los bordes utilizan los mismos diseños que los marcos en las ventanas y puertas de sus casas. Tradicionalmente, la mujer de la cultura maithili, nunca sale de su comunidad y pasa la mayor parte del tiempo escondiendo su cara ante personas extrañas y parientes masculinos. Hoy en día, muchas de estas mujeres han abandonado la casa de sus maridos y ahora viven en el centro, en donde según Burkert encuentran la libertad ${ }^{13}$.

La primera vez que un grupo de mujeres abandonó el pueblo fue en el año 1989. Emil Wendell las propuso decorar los muros de su hotel dentro del parque Nacional de Chitawan en la jungla de Nepal. La excitación que se produjo dentro de la comunidad fue enorme ya que estas mujeres nunca habían viajado anteriormente, excepto cuando abandonaron la casa paterna al contraer matrimonio. Necesitaron el permiso de sus maridos y viajaron con un protector. Tuvieron que soportar las críticas del pueblo que las acusaba de abandonar sus tareas domésticas y familia. Sin embargo, una vez concluido el trabajo, se dieron cuenta de que podían subsistir por sí mismas. La primera exhibición que se hizo sobre los trabajos en papel de las mujeres maithili del JWDC fue en 1990, en la American Library de Katmandú y justo después del Movimiento del Pueblo que abolió la monarquía y estableció el sistema democrático en el país. Las artistas ganaron el reconocimiento y apoyo de la United Nations Development Fund for Women así como de otros donantes. Hoy en día las mujeres maithili del JWDC comparten imágenes e ideas con otras mujeres trabajadoras en el centro que producen cerámicas, textiles y papel maché. A lo largo de los años reciben clases de literatura, dirección, planificación, cuestiones de género, salud y maternidad. Resulta significativa la siguiente declaración de su fundadora, Claire Burkert, hecha para la página web del centro en 1998:

"Hasta la fecha, este trabajo ha sido exhibido en los Estados Unidos, Reino Unido, Alemania y Bélgica. El placer de las artistas al poder desarrollar una profesión y la libertad para expresarse a si mismas a través de la pintura está reflejado en las historias que cuentan en sus declaraciones. Las pinturas cuentan lo que las mujeres maithili han pasado durante generaciones (...) Janakpur es ahora famoso por sus coloridos dibujos sobre papel, tradición que comenzó cuando en el JWDC, junto a una beca de la Ella Lyman Cabot Trust, un grupo de talentosas mujeres fueron seleccionadas para aprender cómo traspasar sus diseños de la pared al papel. Viajaron desde sus pueblos al centro de Janakpur donde, sin perder su originalidad, desarrollaron su capacidad de composición así como el uso del color y la línea (...) Las mujeres artistas decidieron pasarse al pincel y el acrílico al ver que funcionaba mejor que sus pigmentos y técnicas tradicionales sobre el papel (...) Les encantaba venir a la oficina de Janakpur, un ambiente cómodo y libre de la vida severa en el pueblo. A raíz de estar asociadas con un proyecto de desarrollo,estas artistas pronto comenzaron a hacer pinturas relacionadas con temas como el derecho al voto, el no a las drogas, el

13 [En línea] http://jwdconline.com [Consulta: 4 de febrero 2014]. 
sexo con protección.... aunque también continuaron representando los rituales maithili, dioses y leyendas (...) Mi deseo es que esta exhibición ayude a entender mejor a las artistas de Janakpur y crear un interés en cómo su arte evoluciona" 14

La antropóloga Coralynn V. Davis describe cómo, cruzando el puente que va hacia Patán desde Katmandú, llegamos a Kupondole. ${ }^{15}$ Los ciudadanos se refieren a esta zona como Memsahib Row. Memsahib es un término utilizado por los sirvientes de las casas coloniales en India para dirigirse a los colonos, y como extensión un término para referirse a las mujeres coloniales en el sur de Asia. En Memsahib Row destaca el gran número de tiendas turísticas como un servicio económico para los viajeros del primer mundo. Muchas de ellas venden arte Mithila, producido por las mujeres del JWDC. Estos productos que abarcan todo tipo de utensilios decorados, están expuestos en las vitrinas de estas tiendas para ser observados. En el periódico OhmyNews InternationalAwa Suman, presidente del JWDC, declaró en 2013 cómo las artistas mueven por sí mismas el centro y comercializan su arte, por lo que ellas son las únicas beneficiarias de sus productos en venta. Sita Karna, la tesorera del centro, afirma que estas mujeres han tenido que soportar muchas restricciones a su desarrollo socio-económico por motivos culturales, pero que el centro les da una oportunidad de trabajo y sueldo, así como capacidad para el liderazgo. ${ }^{16}$

Otros sistemas de comercialización de este arte están siendo desarrollados como lo es la venta on-line en la ONG Creative Hand Nepal, ${ }^{17}$ y los nuevos centros y fundaciones de apoyo al arte Mithila proliferan. Kachan G. Burathoki declara que hoy en día existen docenas de organizaciones que han seguido el ejemplo del JWDC y que dan empleo a las mujeres maithili. ${ }^{18}$ David Szanton, también antropólogo, presume de haber preservado este arte ancestral a través de la Ethnic Arts Foundation en la que los beneficios de las ventas son devueltos a los artistas, y apoya el Mithila Art Institute en el que los artistas de India y Nepal son entrenados sin coste alguno en esta forma de arte. ${ }^{19}$ (Fig.3.).

También hemos de hablar de la Mithila Yain Art Gallery, de la cual es curador uno de los pocos hombres artistas Mithila: el newarí Shyam Sundar Yadav. Su selección de obras en la galería abarca artistas como Babita Shah y Madan Kala Karn. ${ }^{20}$ (Fig.4.).

14 [En línea] http://www.asianart.com/exhibitions/jwdc/introduction.html [Consulta: 5 de febrero 2014].

15 V. DAVIS, Coralynn: "The Politics of Purchasing Power: Feminist Tourism and Women's Development in Nepal" en Unequal Exchange: Gender and Economies of Power, Vol. 12, University of Michigan, 19971998.

16 Hasta la fecha, el centro ha dado trabajo a 53 artistas, las cuales hacen además otros objetos con su arte, como son cuadernos, espejos, tazas y demás objetos que luego venden al turista por unos precios que oscilan entre las 3 rupias hasta las 4.000. THAPA, Chanda: "Mithila Art Sculpts Bussinesswomen in Nepal” [en línea] OhmyNews International Art and Life, 2006. http://english.ohmynews.com [Consulta:15 de febrero 2014].

17 [En línea] http://www.creativehandnepal.com [Consulta:19 de febrero 2014].

18 BURATHOKI, Kanchan: "Mithila Art in Kathmandu" [en línea] Arts of Nepal, 2011. http://www. artsofnepal.com [Consulta: 3 de febrero 2014].

19 [En línea] http://Mithilartinstitute.org [Consulta: 20 de febrero 2014].

20 [En línea] https://www.facebook.com/MithilaYainArtGallery [Consulta: 20 de febrero 2014]. 


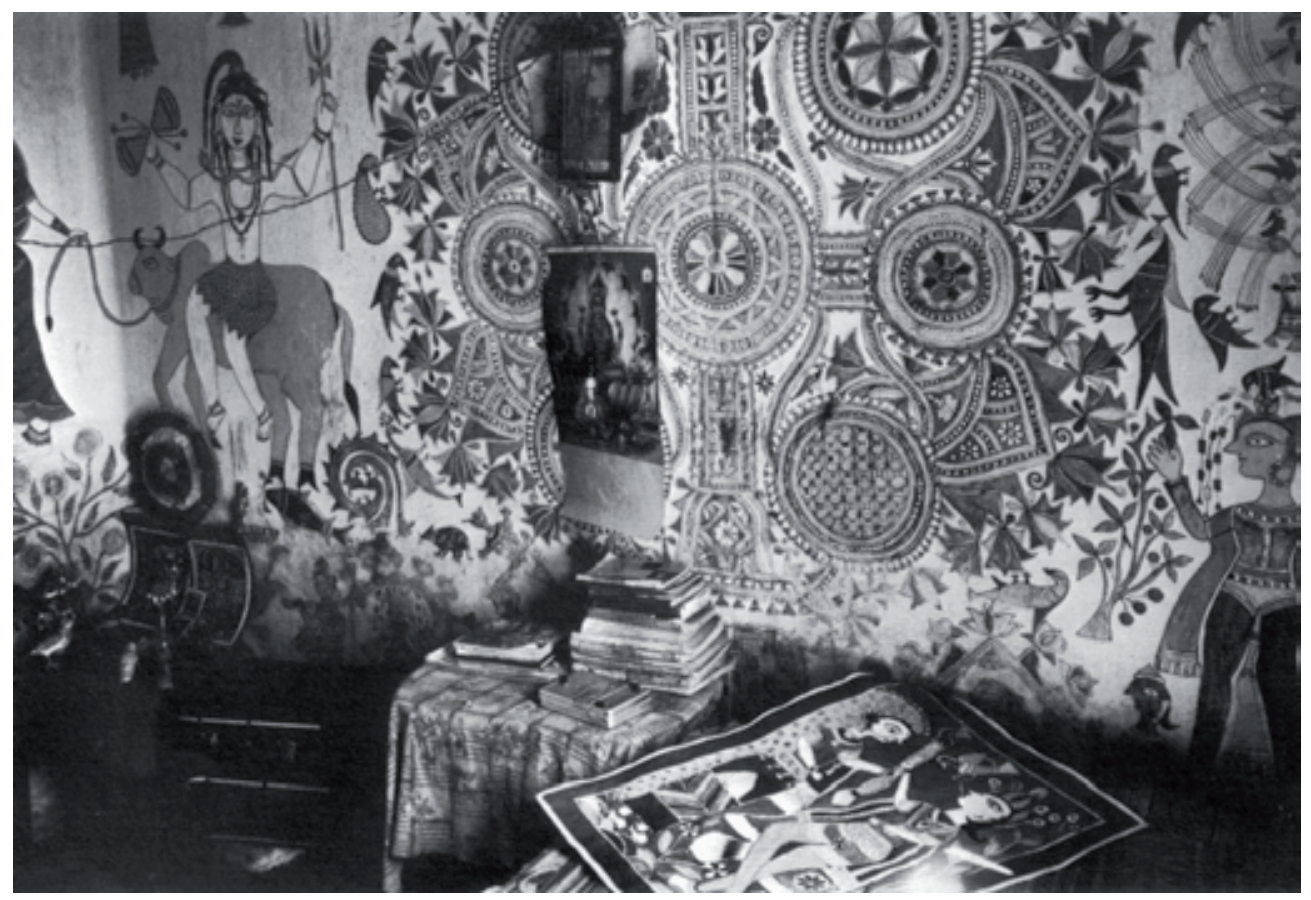

Fig. 3. Yashoda Devi, pintura de pared (detalle), distrito de Madhubani, 1998.

Las artistas Mithila parecen estar contentas con esta nueva práctica de su arte en general, y la sociedad india y nepalí parece estar aceptando este cambio sin mucha resistencia. ¿Tiene algo que ver en todo esto lo que podría denominarse como la "cultura visual internacional" fomentada por la globalización y los medios de comunicación? En su texto sobre estudios visuales, Susan Buck-Morss señala cómo los nuevos medios están incrustados en relaciones globales que son agresivamente desiguales con respecto a sus capacidades de producción y a sus efectos de distribución. ${ }^{21}$ Este hecho simple, tan evidente como profundo, garantiza el potencial democrático de la producción y distribución de las imágenes. Las imágenes son los ladrillos que construyen la cultura y las personas entran así en contacto como espectadores colectivos, aunque no se conozcan los unos a los otros. Es decir, las influencias que estas mujeres reciben debido a la internacionalización de las imágenes, podría ser un factor importante a tener en cuenta en la fácil transformación del arte Mithila en pocas décadas.

Por otro lado, V. Davis es crítica con el JWDC. Afirma que el centro opera en un discurso que prescribe una opresión económica y política a escala internacional y nacional, como lo son las formas globales del feminismo. El desarrollo y el discurso del turista son prácticas que explícitamente apuntan al género y ven a la mujer como un sujeto subordinado ante la sociedad. Los sujetos modernos son definitivamente

21 BUCK-MORSS, Susan: "Estudios visuales e imaginación global” Antípoda Nº, Julio-Diciembre 2009, p. 21-46. 
turísticos en el sentido de que miran a un otro más auténtico contra el cual se mide su modernidad y desde el cual construyen los mitos, como una exhibición para la mirada. Los consumidores de los productos del JWDC buscan la auténtica experiencia del primitivo otro y huyen del turismo masificado. El turista feminista tiene en común con el turismo masivo un deseo por el viaje y la apreciación del cambio, pero a su vez siente nostalgia por la tradición. Una importante motivación para el consumo de este turista es una visión particular y un compromiso, pues ven sus compras como intervenciones feministas políticas. Además, estas pinturas hoy en día muestran una tensión entre la tradición y la modernidad que es heredada del turismo y las representaciones de la mujer maithili como mujer desarrollada, lo que atrae enormemente al turista feminista. ${ }^{22}$

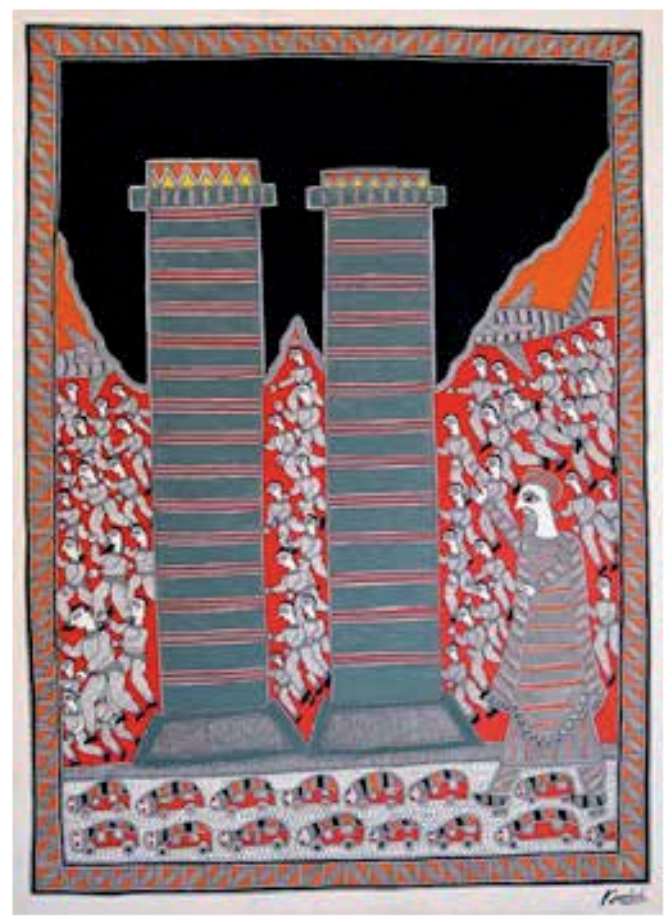

Fig. 4. "The 9/11 attack on the World Trade Towers" Kamelsh Roy, Mithila Art Institute.

22 El JWDC está continuamente representado como una fuerza de empoderamiento de la mujer a través de sus intervenciones económicas, educacionales y sociales. Guías de viaje, tours y mercadillos señalan continuamente el JWDC como lugar que el turista debe visitar. En 1995 V. Davis hizo un cuestionario a los consumidores de arte Mithila preguntándoles que es lo que les motivaba a comprar estas obras. Muchos dijeron que uno de los puntos fuertes era que se trataba de un proyecto de desarrollo, y que su compra ayudaba a estas mujeres. Ante la pregunta de que es el "desarrollo de la mujer" mostró que los encuestados veían el "desarrollo" como una falta. Una falta de oportunidad, de recursos, de habilidades, de (auto) evaluación. El desarrollo debía paliar estas faltas por medio de la educación, los proyectos y el entrenamiento. El desarrollo no está imaginado como una relación global de poder y conocimiento. Para la turista feminista, de desarrollo es una tradición "buena" que acaba con la pobreza y la opresión. 
El Dr. Kailash K. Mistra se lamenta de que la comercialización del arte Mithila haya causado un gran daño a la cultura maithili. Hoy mujeres y hombres están aprendiendo a pintar Mithila por medio de los mercados y las ciudades metropolitanas, en los que los mismos entrenadores desconocen la esencia y la belleza estética de este arte y enseñan a sus estudiantes desde la ignorancia. Además de esto, los temas y diseños de las pinturas son en la mayoría de los casos decididos por los compradores y esto supone una gran amenaza a la originalidad del color, diseño, motivo y sensibilidad de esta forma de arte. En el nombre de la pintura tántrica, vemos estas mujeres hoy pintar cosas completamente distintas de las que pintaban en la tradición Mithila. La comercialización de este arte ha creado incluso el interés de los hombres, los cuales se han decidido a pintar y comercializar también sus propias pinturas Mithila, desconociendo el significado de la mujer en ella. Para ellos, es simplemente una industria de la que pueden sacar un trabajo y pintan cualquier cosa que el comprador solicite en el nombre de la pintura Mithila.

En los últimos años, con la intención de conseguir mejores oportunidades de trabajo, una gran cantidad de población en la zona Mithila, ha emigrado a las ciudades en India y en el extranjero. Muchos se han instalado en estas ciudades, pero continúan apegados a la cultura y tradición maithili. Curiosamente, no hay un matrimonio que no se realice con la decoración del Khobara, celebración que se realiza en las habitaciones de los hoteles y que ha provocado el crecimiento de los compradores del arte Mithila. Esto, para el Dr. Kailash K. Mistra, es la verdadera evolución de este arte. Lamentablemente, las modas del consumismo, el mercado y la actitud de querer vender, han transformado esta forma de arte en algo servicial para el primer mundo.

El impacto de la globalización y el consumismo ha afectado por lo tanto al arte Mithila de manera desmesurada. Hoy en día este arte ha sido expuesto en todo el mundo y su valor en el mercado aumenta cada día, por lo que muchas mujeres maithili están ganando un buen sustento a raíz de su arte. A pesar de que estas mujeres han estado practicando este arte por siglos, es solamente ahora cuando el mundo ha decidido reconocerlas como artistas, e incluso ahora muchos de sus trabajos permanecen en el anonimato. En cualquier caso estas mujeres, muchas de ellas analfabetas, no se consideran a sí mismas productoras de obras de arte y solo unas pocas marcan sus obras con su firma.

Marian López en Geografías de la Mirada manifiesta cómo la desvalorización de la obra artística y su conversión al rango de artesanía, y más concretamente al arte popular, coincide muchas veces con la procedencia económica o geográfica del sujeto. ${ }^{23} 23$ Es el arte de los pobres o el arte de los no occidentales, considerándose dentro de esta categoría no sólo el arte de las mujeres sino el arte de los subalternos, seres empobrecidos o no pertenecientes a occidente, es decir, "los otros". Es necesario que en el campo del arte se desvele la falacia de esta construcción y surja el debate mostrando la ineficacia de estas divisiones estéticas.

También Ely Batra nos presenta claramente las diferencias entre el arte con mayúsculas y el arte popular, bajo el prisma de la división económica, y asociando el arte

23 LÓPEZ, Marian: Geografias de la mirada: Género, creación artística y representación. Universidad Complutense de Madrid, 2001. 
popular al "arte bruto "o menos arte. Basta afirmar que el arte popular es femenino pues "comparte con las mujeres su condición de subalternidad social". Según ella, el arte popular es inferior pero al mismo tiempo, y cuando conviene, se le sublima. ${ }^{24}$

Sin embargo muchas creaciones artísticas han sido realizadas en cooperación y por eso han dado resultados mucho más enriquecedores. El arte popular se nos revela como un arte intrínsecamente solidario, pues la autoría individual se diluye en el seno de un grupo o comunidad y es elemento integrador de los seres humanos. Servían y sirven, a los grupos de mujeres, como espacio de intercambio de vivencias, de creación y transmisión oral de conocimiento vital y artístico, donde participan mujeres de diversas edades y se reconoce la autoridad a través de su experiencia y destreza en la técnica, en general la de más edad. El arte con mayúsculas se ha asociado en la creación plástica con el espacio público que no con el doméstico. Sin embargo, el arte popular vive en el espacio doméstico y se nutre de él. Esto daba cabida a las mujeres que, por el cuidado y la obligación de mantener a la prole, no podían alejarse en exceso, otorgando así al espacio domestico la capacidad de ser también espacio creativo, taller de artistas femeninos. (Fig. 5.).

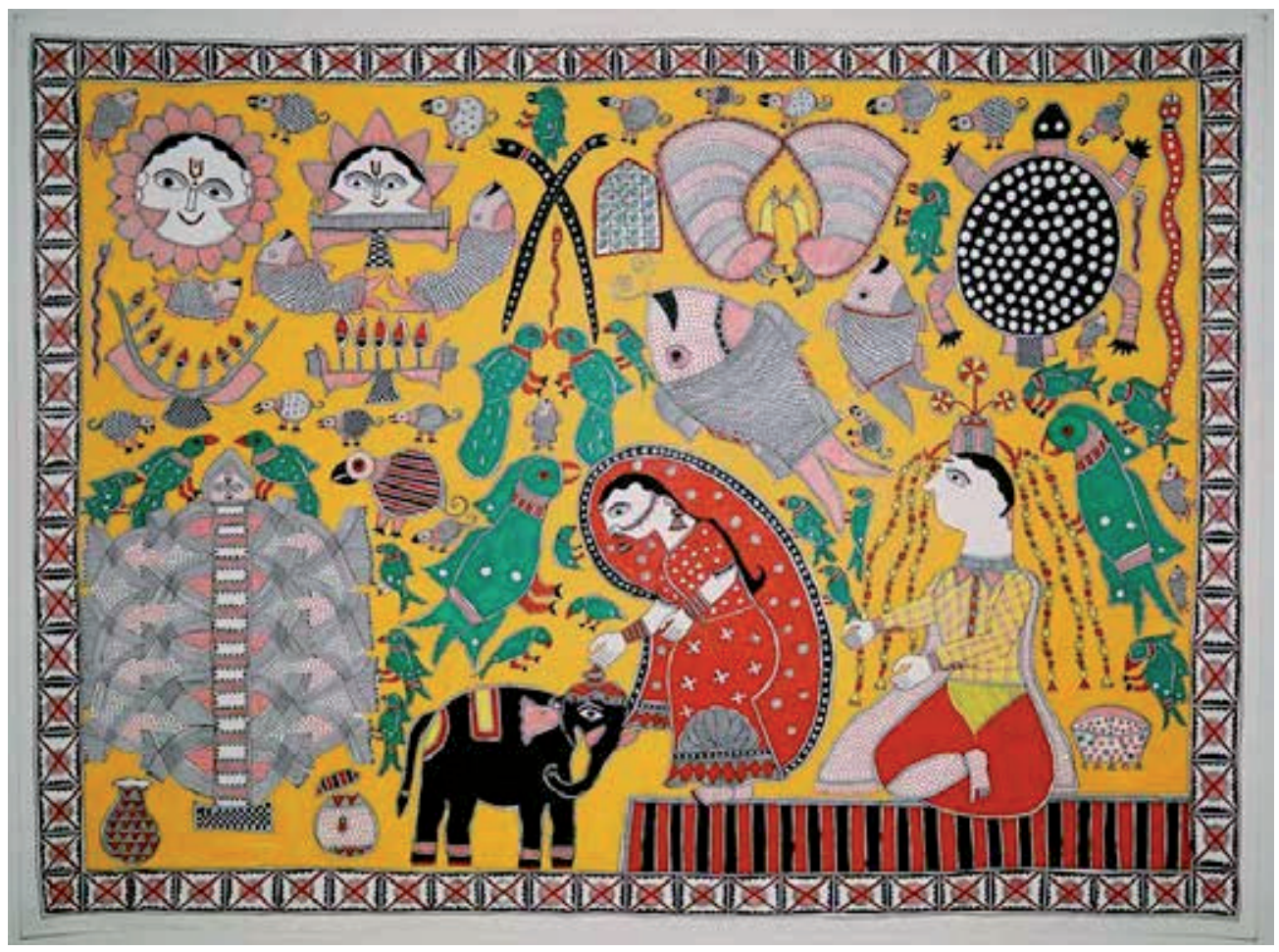

Fig. 5. "Matrimony Icons" Pinki Kumari, Mithila Art Institute. 2004. Ethnic Arts Foundation.

24 BATRA, Ely: En busca de las diablas. Sobre arte popular y género. Tava Editorial, 1994. 
¿Hasta qué punto está la mujer de la cultura maithili subyugada por la sociedad patriarcal? El análisis del término "mujer del tercer mundo" por parte del "feminismo del primer mundo", y todas las creencias y mitos sobre esta mujer que este término conlleva podría ayudarnos a desvelar la realidad de esta situación. Ambos términos se refieren a un sistema de formas de dibujar las relaciones globales entre las naciones del mundo tras la Segunda Guerra Mundial. La frase "feminismo del primer mundo" resalta en una generalización que engloba a todos los feminismos y su nombramiento ha reconocido y cuestionado los límites de la escuela feminista en occidente, particularmente en relación con las "mujeres del tercer mundo". Por supuesto la frase "mujer del tercer mundo" es también problemática, pues engloba también de manera similar las experiencias y representaciones de diferentes mujeres en normalmente países que antes fueron colonias, marcando una categoría conceptual. ${ }^{25}$ Para Spivak, los intentos de construir a la "mujer del tercer mundo" como un significado recuerda la hegemónica definición de la literatura.

Por otro lado, el término "patriarcado" se refiere a esos sistemas que dan poder a los hombres y marginan a las mujeres. Impone un cierto sistema de representación del individuo que lo define como "normal" o "verdadero" y crea un orden social. Como el colonialismo, el patriarcado permanece entre la niebla enfrentándose a su autoridad y puede ser traicionero, por ser una generalización de muchos tipos distintos de patriarcado. Para muchas mujeres colonizadas en el tercer mundo, el patriarcado occidental ha tenido profundos efectos en los roles de su propia sociedad por haber impuesto su propio modelo social. Esto nos lleva a una pregunta clave: ¿los valores postcoloniales perpetúan o cuestionan los valores patriarcales? ¿Pueden ser estos valores cómplices de la opresión de la mujer? El feminismo occidental sufre de etnocentrismo, presumiendo que la solución que las mujeres blancas han ideado para combatir el patriarcado es válida para todas las mujeres. Como consecuencia, los problemas de la raza o la cultura han sido olvidados y la diferencia omitida en favor de una teoría generalizada, lleva al fracaso. Además de eso, la mujer blanca no ha querido verse a sí misma como un tipo de opresora de la mujer asiática o negra, incluso cuando adopta posiciones benevolentes hacia ellas. Mohanty reconoce que la atención del feminismo occidental a la mujer del tercer mundo es valiosa en el sentido de fomentar los vínculos internacionales, pero le preocupan los términos con los que se usa esta relación. "Tercer mundo" es un término que permanece inferior al "primer mundo". En un contexto feminista, Mohanty se lamenta que se trate de encajonar a las sociedades en preconcebidos marcos sin referencias, y sin cuestionarse jamás que quizá esos marcos puedan ser inapropiados, y así se contextualiza la sociedad. En el texto de Spivak Can the Subaltern Speak? vemos que no podemos encontrar al subalterno en nuestros propios términos pues estamos condenados a rendir su consciencia al recurrir a términos dominantes. Es decir, en el acto de dar voz y visibilidad al subalterno, irónicamente este desaparece y es silenciado. ${ }^{26}$

25 MCLEOD, John: "Post colonialism and Feminism" en Beginning Post colonialism. Manchester University Press, 2000.

26 CHAKRAVORTY SPIVAK, Gayatri: "Can the Subaltern Speak?" en Marxism and the Interpretation of Culture. Cary Nelson and Lawrence Grossberg, 1988. 
Estos problemas empeoran al tratar temas de género, pues las representaciones del subalterno tienden a priorizar al hombre y mientras la mujer permanece hundida en la sombra. ¿Puede la mujer, confinada en la sombra por la historia y la representación, ser alguna vez escuchada al hablar? Spivak dice que no es tanto que la mujer subalterna no hable -pues hay muchas formas de hablar que no tienen por qué ser verbales- es que los otros no saben cómo escucharla. La subalterna no puede hablar porque sus palabras no pueden ser debidamente interpretadas. Por tanto, el silencio de la mujer subalterna es un resultado de fallo de interpretación, no de articulación.

La feminista como turista, o feminista como consumidora internacional, es el modelo de la carga de responsabilidad de la mujer blanca o el discurso colonial. En los estudios de la turista feminista la distancia con respecto al hogar resulta fundamental para definir este marco de referencia en concepto de lo internacional. El modelo de turista feminista se basa en dos culturas diferentes y por tanto no hay bases comunes entre ambas culturas. Se colapsa la idea de lo global y lo local. El problema implicado en la estrategia feminista como exploradora es que la globalización es un fenómeno económico, político e ideológico, que somete activamente al mundo y a sus diversas comunidades a regímenes materiales y discursivos que están conectados y son interdependientes. Liliana Suarez Navaz destaca la generalización bajo la etiqueta de "mujer del tercer mundo", ya que existe una enorme diversidad de situaciones diferentes que bajo este término quedan olvidadas. Así, se aísla la dimensión de género de las múltiples estructuras de poder, en las que las mujeres estudiadas están situadas, y se llega a conclusiones apresuradas respecto a las causas de la subyugación de la mujer ${ }^{27}$.

La consideración de las mujeres como objetos de explotación o subordinación, más que como agentes activos conscientes de sí mismas y de su entorno, hacen del feminismo una misión civilizadora que se pone en marcha sin preguntar a las mujeres afectadas. Para Mohanty, la palabra "desarrollo" es asumida como "desarrollo económico". ${ }^{28}$ Los conceptos de trabajo y producción son categorías muy arraigadas en la cultura del capitalismo y la sociedad moderna, por lo que son conceptos inadecuados a la hora de describir otras sociedades no europeas y no capitalistas. ¿Puede la economía capitalista iluminar las sociedades medievales y primitivas? Según Baudrillard la respuesta es no, pues estas sociedades se organizan en términos económicos y productivos de una manera diferente. Lo mágico, lo religioso y lo simbólico, son relegados a la marginalidad por causa del factor económico en la teoría capitalista. ¿Debería el feminismo apropiarse de los conceptos marxistas y capitalistas sin pararse a pensar los límites culturales e históricos de estos "Occidente" y "tercer mundo" retienen un valor político y explicativo en un mundo que apropia y asimila el multiculturalismo y la diferencia a través de la mercantilización y el consumo.

27 SUAREZ NAVAZ, Liliana: "Colonialismo, gobernabilidad y feminismos postcoloniales" en Descolonizando el feminismo. Teorías y prácticas desde los márgenes. España: Ediciones Cátedra, 2008.

28 TALPADE MOHANTY, Chandra: "Bajo los ojos de Occidente: academia feminista y discursos coloniales" en Descolonizando el feminismo. Teorías y prácticas desde los márgenes. España: Ediciones Cátedra, 2008. 
Por otro lado, Maura Reilly dice que en lugar de descubrir el poder en la diferencia de nuestros problemas compartidos como mujeres, esta diferencia ha pasado a significar una fuente de desunión entre nosotras. Sin embargo, esta diferencia no tiene porqué ser una amenaza para la alianza entre mujeres, pues solo mediante el entendimiento de nuestras "diferencias comunes" la solidaridad es alcanzada. ${ }^{29}$

En la segunda ola feminista ocurrida en $\operatorname{los} 70$ y los 80 , la guerra contra el sexismo tenía preferencia a la preocupación sobre otros temas como el racismo o la homofobia. Había un miedo general en el que se insistía que si nos enfocamos en las diferencias de raza en lugar de en el sexo/género se disolvería el largo trabajo de las feministas que luchan por el poder de la mujer. Maura Reilly dice que este argumento es hoy en día utilizado por muchos en contra de los que están interesados en perseguir un feminismo multicultural y transnacional, por miedo a que su foco, en las múltiples diferencias de raza, religión, clase, sexual etc. lleve a un relativismo político o divida el movimiento feminista en múltiples -istmos, disperso y sin un punto central. Homi K. Bhabha advierte sin embargo que por el problema recurrente de la noción de "igualdad", el liberalismo contiene un concepto no diferenciador del tiempo cultural, sobre el cual el discurso liberador trata de normalizar la diferencia cultural, sin reconocer así la línea del borde temporal de culturas parciales y minorías ante la cultura hegemónica. ${ }^{30}$

Lo que no podemos negar, es que la cultura maithili se ha dividido entre la tradición y el consumismo típico de la era moderna, convirtiéndose a sí misma en un híbrido multicultural. Los multiculturalistas tratan democráticamente de incluir todas las culturas en la sociedad y aceptarlas pero las siguen nombrando de forma exclusiva. La hibridación y el híbrido es una construcción de la autoridad cultural dentro de unas condiciones de antagonismo y desigualdad política. Las agencias híbridas dan su propia visión de la comunidad y una narración a las minorías que la ocupan.

Hemos tratado en este estudio una historia del arte Mithila que ha abarcado desde la tradición hasta hoy en día, contextualizando a su vez las diferentes teorías sobre lo que es la situación global de la cultura actual. Como conclusión, podemos afirmar que el arte Mithila se ha transformando con el objetivo de ser un arte vendible, rompiendo con las tradiciones de su cultura milenaria por la ganancia de unas monedas que en teoría parecen ser muy necesarias para la mujer de la cultura maithili y le da la oportunidad de ser "libre". Personalmente, me pregunto por qué asociamos siempre la libertad con el dinero en la cultura actual. ¿Son realmente más libres las mujeres maithili con unas rupias más? Las ONGs y organismos que defienden esta teoría para justificar la venta de productos Mithila, no consideran en qué se gastan las mujeres este dinero o a quién se lo dan. La realidad es que el desconocimiento de la verdadera cultura maithili nos impide saber lo que piensa la cultura maithili. Vivimos en un mundo de vorágine y consumismo en el que arrastramos todo a nuestro paso con unos billetes en la mano. Aparentemente, parece que "sabemos todo" sobre la cultura maithili pero nunca hemos estado más lejos de entender las culturas ajenas

29 REILLY, Maura: "Curating Transnational Feminisms" en Feminist Studies 36:1, Primavera 2010, p. 156-173.

30 K. BHABHA, Homi: “Culture's In-Between” en The Location of Culture, Routledge, 1994. 
como lo estamos ahora. Lo peor de esto es que estamos arrastrando con nosotros a esas mismas culturas en el abismo de la ignorancia y la destrucción al "comprarlas" con nuestro dinero. Bhabha dice que en este punto lo necesario es desconectar de la vorágine. El entendimiento del pasado y del futuro, la solidaridad, es lo único que nos permitirá trabajar a través del presente y salir de él. Y es salir del presente lo que nos liberara del determinismo histórico inevitablemente repetido y "sin diferencias" (entre comillas). Es necesario por tanto aprender a ver y escuchar a la diferencia, y aceptarla como tal si queremos aprender realmente sobre las otras culturas.

El arte Mithila no debería de ser visto como la consecuencia de la colonización capitalista de este arte, sino a partir de la comprensión y conocimiento de la propia cultura maithili y los acontecimientos históricos sufridos por dicha cultura en el mundo actual. Las agencias culturales híbridas nos dan su propia visión de la comunidad y narran a las minorías que la ocupan. ¿Resulta entonces la transformación del arte Mithila una simple estrategia de supervivencia en el mundo cada vez más globalizado? A ésta pregunta clave, respondería con otra pregunta: ¿Existe en realidad el "arte homogéneo"? ¿Qué arte es puro? ¿Qué cultura jamás ha sido transformada o influenciada por otra cultura? Según las teorías expuestas, el arte Mithila se ha transformando con el objetivo de ser un arte vendible, rompiendo con las tradiciones más arraigadas de su cultura milenaria por la ganancia de unas monedas que suponen la libertad y el desarrollo de la mujer Maithili. ¿Hubiese cambiado de esta manera el arte de Mithila sin esta motivación aparente? Desde mi punto de vista, concluiría finalmente que la transformación del arte de Mithila no ha ocurrido tanto por la "libertad de la mujer del tercer mundo" como por la adaptación de este arte a los nuevos tiempos. Esto no significa que la estética o el valor de este arte hayan disminuido, pues las obras de Mithila sobre papel reflejan una cultura que sigue sin duda alguna cautivándonos con su belleza. La transformación de la cultura Maithili ha sido por tanto un paso inevitable y una estrategia razonable de supervivencia de dicha cultura dentro de las nuevas reglas que rigen la sociedad global. No creo por tanto que con el cambio se haya perdido la cultura Maithili, al contrario creo que en el corazón del pueblo esta cultura sigue muy viva, lo cual se refleja constantemente en la calidad de sus dibujos a papel, representando una evolución que parte de su propia cultura milenaria. 